anti-inflammatory agents. In: Gilman AG, Goodman LS, Rall TW, Murad F, eds. The pharmacological basis of therapeutics. New York: Macmillan, 1985: 674-715.

3 Cooper KB, Veale WL. Effects of temperature on breathing. In: Fenn WO, Rahn H, eds. Handbook of physiology. Section 3, vol II. The respiratory system. Washington DC: American 3, vol II. The respiratory system. Wash
Physiological Society, 1986: $691-702$.

4 Campbell H, Byass P, O'Dempsey TJ. Effect of body temperature on respiratory rate in young children. Arch Dis Child 1992; 67: 664 .

5 White NJ, Warrell DA. The management of severe malaria

In: Wernsdorfer WH, McGregor I, eds. Malaria. Vol I.
Edinburgh: Churchill Livingstone, 1988: 865-88.

6 Corbett CEP, Duarte MIS, Lancellotti CLP, Silva MALG, Andrade HF. Cytoadherence in human falciparum malaria as a cause of respiratory distress. F Trop Med Hyg 1989; 92: 11220.

7 Punyagupta S, Srichaikul T, Nitiyanant P, Petchlai B. Acute pulmonary insufficiency in falciparum malaria: summary of 12 cases with evidence of disseminated intravascular coagulation. Am $\mathcal{F}$ Trop Med Hyg 1974; 23: 551-9.

8 Harinasatu T, Bunnag D. The clinical features of malaria. In: Wernsdorfer WH, McGregor I, eds. Malaria. Vol I. Edinburgh: Churchill Livingstone, 1988: 709-35.

\title{
Computed tomography in acute bacterial meningitis
}

One of the factors that determines whether an investigation is done is the ease of its availability. This is particularly important when the patient is acutely ill and the investigation can only be done in another hospital. Clearly in such circumstances the risk involved in moving the patient must be balanced against the potential benefit to be derived from the investigation. Until recently in Britain computed tomography was available at only a relatively few hospitals and this clinical decision needed to be taken fairly frequently but as more hospitals acquire the facility so the risks of transfer over a long distance enter into the equation less often. Nevertheless the question still needs to be asked, 'Is a CT scan likely to be helpful?'

Between January 1986 and October 1989, 33 children with acute bacterial meningitis were transferred from other hospitals to the Hospital for Sick Children, Great Ormond Street, for computed tomography. Robert Heyderman and his colleagues have recently described the clinical and radiological features of 30 of these patients (Developmental Medicine and Child Neurology 1992; 34: 870-5).

The findings on computed tomography significantly influenced management in three patients. One 18 month old child referred because of clinically suspected raised intracranial pressure was shown to have gross communicating hydrocephalus and a ventriculoperitoneal shunt was inserted. Of the other two patients one had a subdural empyema and the other a large subdural effusion, both needing surgery. These two children had both developed progressive focal neurological signs. Patients with non-progressive focal neurological signs were not helped by the scanning. Similarly the investigation was unhelpful in the management of patients with repeated seizures $(n=3)$ or prolonged fever $(n=8)$. Three patients in this series were shown to have a cerebral infarct but none of them had focal neurological signs. Fifteen children were suspected to have raised intracranial pressure on clinical grounds and five of these showed brain oedema on scanning. Four of these five had signs of brainstem death soon after transfer.

The authors conclude that computed tomography is usually not helpful in the management of children with acute bacterial meningitis and it can not be used to eliminate the risk of coning when considering whether to perform a lumbar puncture. Most children with meningitis do not need computed tomogram ( $c f$ tuberculous meningitis, see Archivist 1991 pages 151 and 1226). The main indication for the investigation is a progressive focal neurological deficit but I suspect that many children with impaired consciousness will continue to be scanned, especially when the investigation is available on the spot. This paper provides no information about the value of neurological intensive care including intracranial pressure monitoring. 